\title{
Nachlese zum 14. Juni 2011
}

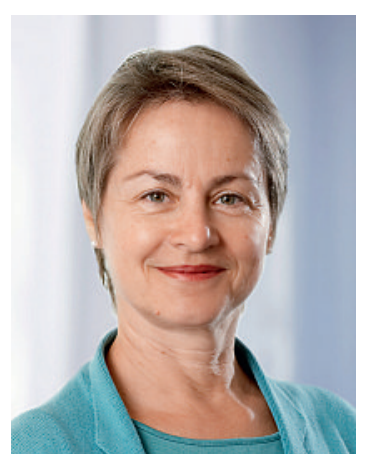

Gleich mehrere Jubiläen gab es dieses Jahr im Juni zu feiern: 20 Jahre ist es her seit dem ersten Frauenstreik in der Schweiz. Am 14. Juni 1991 legte gegen eine halbe Million Schweizer Frauen ihre Arbeit nieder, beflügelt vom Motto «Wenn frau will, steht alles still».

Im ganzen Land fanden Kundgebungen und Aktionen statt, rund 200000 Frauen diskutierten in Betrieben, Schulen, an Universitäten und auch an Spitälern über Lohndiskriminierung, ungleiche Chancen im Berufsleben, Schwangerschaftsabbruch, Mutterschaftsversicherung und Kindertagesstätten bis zu sexueller Belästigung am Arbeitsplatz und sexueller Gewalt gegen Frauen. Es war die grösste politische Kundgebung seit der Gründung des Bundesstaates überhaupt! Anlass für den 14. Juni 1991 war damals ebenfalls ein Jubiläum: Am 14. Juni 1981 war der Verfassungsartikel «Gleiche Rechte für Mann und Frau» in Kraft getreten - der Streik zehn Jahr später war Ausdruck einer tiefen Frustration angesichts der Tatsache, dass der formalen Gleichstellung in der Verfassung nach wie vor unzählige Ungleichheiten im täglichen Leben gegenüberstanden. Ein weiteres Jubiläum verdient ebenfalls, erwähnt zu werden: Vor 40 Jahren hat die Schweiz als eines der letzten Länder des ganzen Erdballs überhaupt das Frauenstimmrecht eingeführt, am 6. Juni 1971 konnten die Frauen zum ersten Mal in der Schweiz an einem eidgenössischen Abstimmungssonntag an die Urne.

\section{Noch stehen Frauen, die Familie und Beruf unter einen Hut bringen wollen, vor herkulischen Herausforderungen.}

Frauen haben in den letzten 20 Jahren einiges erreicht und stellen aktuell die Mehrheit in der Landesregierung. Das Recht auf gleichen Lohn für gleiche Arbeit ist damit aber noch keineswegs garantiert - an dieses Versäumnis wurde denn auch am diesjährigen 14. Juni nachdrücklich erinnert. Zwar gewährleistet mittlerweile eine Mutterschaftsversicherung einen minimalen Schutz und ist auch Ausdruck eines Sinneswandels - aber noch stehen Frauen, die Familie und Beruf unter einen Hut bringen wollen, vor herkulischen Herausforderungen.

Dies gilt augenfällig auch im ärztlichen Berufsfeld, der weiblichen Lebensentwürfen, die sich nach wie vor - nicht immer, aber häufig genug - um die Frage von Vereinbarkeit von Familie und Beruf drehen, nicht Rechnung trägt. Barbara Weil spannt in dieser Ausgabe der Schweizerischen Ärztezeitung (Seite 926) den Bogen von der Antike bis heute und fragt nach den Bedingungen der weiblichen Berufstätigkeit. In der nächsten Ausgabe wird eine junge Frau zu Wort kommen, die sich bereits während dem Studium mit diesen Fragen auseinandersetzt, eine Kollegin schaut auf ihr reiches Berufs- und Familienleben zurück. Beide weisen auf einen kritischen Zeitpunkt einer Ärztinnenlaufbahn hin: Die Weiterbildungszeit fällt mehr oder weniger in die Zeit der Familienbildung. Hohe Arbeitsbelastungen und Arbeitszeiten, die sich nur an den Bedürfnissen des Betriebes orientieren, treiben junge Frauen, junge Eltern überhaupt, in eine nicht akzeptable Überforderung! Spitäler sind hier vorrangig gefordert: Ist es wirklich nicht zu umgehen, dass Frauen sich aufreiben müssen zwischen Arbeit und Familie? Dass begabte und qualifizierte Frauen ihre berufliche Entwicklung vorzeitig stoppen, weil der Arbeitsdruck zu gross ist und «Teilzeitstelle» für viele Chefs noch immer ein Fremdwort ist? Können wir es uns überhaupt noch leisten, auf leitende Ärztinnen und Chefärztinnen zu verzichten, nur weil die Spitäler zu unflexibel sind, um Teilzeitstellen auf allen Hierarchiestufen anzubieten?

\section{Spitäler sind gefordert: Können wir es uns noch leisten, dass qualifizierte Frauen ihre berufliche Entwicklung stoppen, weil Teilzeitstellen für viele Chefs nach wie vor undenkbar sind?}

Auch nach der Weiterbildung sind die Probleme nicht gelöst. Statt sich darüber zu wundern, dass Frauen auch als niedergelassene Ärztinnen lieber in einer Stadt arbeiten möchten, könnten Gemeinden, denen eine gute ärztliche Versorgung ein Anliegen ist, gute Kinderkrippen, Horte, Mittagstische usw. anbieten. Und last but not least müssen auch die Frauen - und Männer - selber sich etwas einfallen lassen: Jobsharing auch in der eigenen Praxis und Zusammenarbeit jeglicher Art.

Sagen wir es deutlich: Angesichts der Feminisierung der Medizin und des sich abzeichnenden Ärztemangels wird die Frage der Vereinbarkeit von Familie und Beruf auch zu einer Frage, wie die medizinische Versorgung im Land überhaupt gewährleistet werden kann.

Dr. med. Christine Romann, Mitglied des Zentralvorstands der FMH, Verantwortliche Ressort Gesundheitsförderung und Prävention 